\title{
CD70 (TNFSF7) is expressed at high prevalence in renal cell carcinomas and is rapidly internalised on antibody binding
}

\author{
PJ Adam ${ }^{1,5}$, JA Terrett ${ }^{2,5}$, G Steers ${ }^{3}$, L Stockwin', JA Loader', GC Fletcher', L-S Lu², BI Leach', S Mason', \\ AC Stamps ${ }^{*, 1}$, RS Boyd ${ }^{4}$, F Pezzella $^{3}$, KC Gatter $^{3}$ and AL Harris ${ }^{3}$ \\ 'Celltech Antibody Centre of Excellence, 216 Bath Road, Slough, Berkshire SLI 4EN, UK; ${ }^{2}$ Medarex Inc., 521 Cottonwood Drive, Milpitas, CA 94022, \\ USA; ${ }^{3}$ Cancer Research UK Molecular Oncology Laboratories, Weatherall Institute of Molecular Medicine, John Radcliffe Hospital, Oxford OX3 9DS, UK: \\ ${ }^{4}$ MRC Toxicology Unit, Hodgkin Building, University of Leicester, P.O. Box 138, Lancaster Rd, Leicester LEI 9HN, UK
}

In order to identify potential markers of renal cancer, the plasma membrane protein content of renal cell carcinoma (RCC)-derived cell lines was annotated using a proteomics process. One unusual protein identified at high levels in A498 and 786-O cells was CD70 (TNFSF7), a type II transmembrane receptor normally expressed on a subset of $\mathrm{B}, \mathrm{T}$ and $\mathrm{NK}$ cells, where it plays a costimulatory role in immune cell activation. Immunohistochemical analysis of CD70 expression in multiple carcinoma types demonstrated strong CD70 staining in RCC tissues. Metastatic tissues from eight of I I patients with clear cell RCC were positive for CD70 expression. Immunocytochemical analysis demonstrated that binding of an anti-CD70 antibody to CD70 endogenously expressed on the surface of A498 and 786-O cell lines resulted in the rapid internalisation of the antibody-receptor complex. Coincubation of the internalising anti-CD70 antibody with a saporin-conjugated secondary antibody before addition to A498 cells resulted in 50\% cell killing. These data indicate that CD70 represents a potential target antigen for toxin-conjugated therapeutic antibody treatment of RCC. British Journal of Cancer (2006) 95, 298-306. doi:I0.1038/sj.bjc.6603222 www.bjcancer.com (C) 2006 Cancer Research UK

Keywords: proteomics; renal cell carcinoma (RCC); CD70; antibody; internalisation

\begin{abstract}
Advanced renal cell carcinoma (RCC) is generally resistant to chemotherapy treatment (Yagoda, 1995; Motzer, 1999), and immunotherapy with interferon-alpha and interleukin-2 (IL-2) as single agents or in combination with the chemotherapeutic agent 5 -fluorouracil is currently used as systemic treatment for some cases. Response rates remain low at around 15\%, and the toxicity of high-dose IL-2 limits its use (Krown, 1987; Muss, 1998; Kammula, 1998; van Herpen et al, 2000). Targeted therapeutics are relatively new to the oncology field, most acting via the inhibition of mitotic signalling kinases. Therapeutic antibodies have been exploited for their target specificity and low toxicity, and many have already been approved for clinical use, including herceptin (trastuzumab) and erbitux (cetuximab), which target the activities of cell-surface receptors, her2 and EGFR, respectively, in solid tumours. Antibodies can also be used to specifically deliver cytotoxic drugs to tumour cells as immunoconjugates that bind to, and internalise with, highly expressed cell surface antigens. An example of an antigen found to be overexpressed in RCC is carbonic anhydrase IX (CA9), which is the target for the monoclonal antibody (mAb) G250 (Pastorek et al, 1994; Uemura et al, 1999; Grabmaier et al, 2000; Li et al, 2001; Bui et al, 2003). Immunoscintigraphy of RCC patients dosed with iodine-131labelled G250 demonstrated tumour targeting to metastatic sites (Divgi et al, 1998; Steffens et al, 1999; Kennett, 2003).
\end{abstract}

\footnotetext{
*Correspondence: Dr A Stamps;

E-mail: alasdair.stamps@celltech.ucb-group.com

${ }^{5}$ These authors contributed equally to this work.

Received 22 February 2006; revised 8 May 2006; accepted I I May 2006
}

The aim of this study was to identify other cell-surface proteins specifically associated with RCC that might be suitable targets for antibody-targeted cytotoxic therapeutics. To compile a list of candidate RCC cell-surface proteins, we used a previously described proteomics approach adapted for breast cancer cell lines (Adam et al, 2003) using plasma membrane preparations from the A498, SW839 and CAKI-2 RCC-derived cell lines. As described previously (Adam et al, 2003), potential targets were analysed further using real-time quantitative RT-PCR and immunohistochemistry to quantify expression in normal tissues and clinical RCC samples. We found CD70, a type II transmembrane cell-surface protein of the tumour necrosis factor (TNF) receptor family (Goodwin et al, 1993; Bowman et al, 1994; Hintzen et al, 1994), to be expressed at high levels in RCC, with expression retained in metastatic RCC tissues. We also show that CD70 is rapidly internalised on binding of an anti-CD70 $\mathrm{mAb}$ in RCCderived cell lines and that this property allows specific killing of the CD70-expressing cells by incubating the primary antibody with a saporin-conjugated secondary antibody. These data demonstrate that $\mathrm{CD} 70$ is a selective biomarker for the diagnosis and/or treatment of RCC using cytotoxic immunotherapy.

\section{MATERIALS AND METHODS}

\section{Preparation of membrane fractions and mass spectrometry}

Membrane fractions from the A498 and SW839 RCC-derived cell lines were prepared from $2 \times 10^{8}$ cells as described previously (Adam et al, 2003). Purified membrane proteins were resolved 
on a $20 \mathrm{~cm} 6 \%$ Laemlli one-dimensional gel (BioRad, Hemel Hempstead, UK) and $0.5 \mathrm{~mm}$ slices were subjected to trypsinolysis and prepared for MALDI-TOF mass spectrometry (Voyager STR, Applied Biosystems, Framingham, MA, USA) as previously described (Adam et al, 2003). Selected peptide masses for CD70 $(\mathrm{M}+\mathrm{H})=1217.6$ and 1142.6 were characterised further by MS/MS using a tandem quadrupole TOF mass spectrometer equipped with a nanospray ion source (Micromass UK Ltd, Manchester, UK). Using the SEQUEST search program (Link et al, 1999), ion fragmentation mass spectra of these peptides were sequenced by $\gamma$ and $\beta$-ion analysis, and identified by comparison with a FASTA database of public domain proteins constructed of protein entries in the non-redundant database held by the National Center for Biotechnology Information (http://www.ncbi.nlm.nih.gov) and ExPasy (http://www.expasy.com).

\section{Human tissues and cell lines}

A range of normal frozen tissues (brain, breast, kidney, liver, tonsil, lymph nodes, skin and thyroid) and tumour tissues were obtained from the Cellular Pathology Department at the John Radcliffe Hospital, Oxford, UK together with pre-sectioned primary and metastatic RCC tissue from Ardais Corporation, Lexington, MA, USA. Frozen sections of $8 \mu \mathrm{m}$ were cut for each tissue on a cryostat (Leica Microsystems (UK) Ltd, Milton Keynes, Bucks, UK) and mounted on Snowcoat X-tra glass slides (Surgipath Europe Ltd, Peterborough, UK). Following airdrying for $30 \mathrm{~min}$ at room temperature (RT), each section was immersed in $100 \%$ acetone for $15 \mathrm{~min}$, air dried and then stored at $-20^{\circ} \mathrm{C}$ until required. The human RCC-derived cell lines SW839 (American Type Culture Collection (ATCC): HTB-49), A498 (ATCC: HTB-44), 786-O (ATCC: CRL-1932) and ACHN (ATCC: CRL-1611) were cultured at $37^{\circ} \mathrm{C}$ in a humidified atmosphere of $95 \%$ air and $5 \% \mathrm{CO}_{2}$ in growth media specified by the supplier (ATCC, Manassas, VA, USA). A variety of B-cell malignancy derived cell lines (RAMOS, BL16, BL58, AS283, MUTU-III, K562, U937) were kindly provided by Professor Martin JS Dyer, Department of Haematology, University of Leicester, UK. Human PBMCs were purified from donor blood (from the National Blood Service, Bristol, UK) by diluting 1:2 in PBS, layering over a $20 \mathrm{ml}$ ficol solution and spinning at 2500 r.p.m. for $20 \mathrm{~min}$.

\section{Flow cytometry}

Harvested cell lines were washed in Dulbecco's Phosphate buffered Salt Solution (DPBS) and resuspended at $1 \times 10^{7} \mathrm{cells}^{-1}$. Adherent cells were detached by incubation in $0.5 \mathrm{~mm}$ EDTA in PBS. Peripheral blood mononuclear cells (PBMCs) were prepared by Ficoll density centrifugation. An aliquot $(100 \mu \mathrm{l})$ of cell line or PBMCs was then added to each well of a 96-well plate in triplicate. The cells were pelleted by centrifugation and washed once in ice-cold DPBS. DPBS $+5 \%$ BSA, containing $1 \mu \mathrm{g} \mathrm{ml}^{-1}$ of anti-CD70 antibody BU69 (Ancell Corporation, Bayport, MN, USA), was then added to each well $(200 \mu \mathrm{l})$. For control wells, anti-CD70 antibody was substituted for IgG1 isotype control (Serotec Ltd, Oxford, UK). The cells were then incubated on ice for $60 \mathrm{~min}$ then washed three times in cold DPBS and resuspended in DPBS $+5 \%$ BSA containing $10 \mu \mathrm{g} \mathrm{ml}^{-1}$ of goat anti-mouse Alexa ${ }^{488}$ conjugate (Molecular Probes Inc., Eugene, OR, USA). Cells were then incubated for a further $60 \mathrm{~min}$ on ice, followed by three washes in DPBS, where the final wash contained propidium iodide $\left(10 \mu \mathrm{g} \mathrm{ml}^{-1}\right)$. Acquisition of data was performed using a FACScalibur flow cytometer (FL1 + FL3) with an MPM modification and all subsequent data analysis was performed using CellQuest Pro Software (Becton-Dickinson).

\section{Immunohistochemistry}

Tissue sections were first allowed to warm to RT, then immersed for $10 \mathrm{~min}$ in $3 \%$ hydrogen peroxide in water to quench endogenous peroxidase activity followed by washing in water and then tris-buffered saline (TBS) $\mathrm{pH}$ 7.6. A monoclonal mouse anti-human CD70 antibody, HNE.51 (DakoCytomation, Ely, UK), which has been well characterised for CD70 staining on frozen tissues, was applied to the tissues $\left(2 \mu \mathrm{g} \mathrm{ml}^{-1}\right.$ in TBS $)$ for $90 \mathrm{~min}$ followed by two $5 \mathrm{~min}$ washes in TBS. Secondary antibody from the DakoCytomation Envision anti-mouse system (DakoCytomation, Ely, UK) was applied for $30 \mathrm{~min}$ followed by two washes in TBS. Detection was achieved by a $5 \mathrm{~min}$ incubation in the presence of 3,3'-diaminobenzidine $(\mathrm{DAB}+)$ substrate chromogen, which results in a brown-coloured precipitate at the antigen site. Sections were counter-stained in Gills II haematoxylin (Surgipath Ltd, Richmond, IL, USA) and mounted under glass coverslips using aqueous mounting medium (Faramount, DakoCytomation, Ely, UK).

\section{Immunocytochemical analysis of antibody internalisation}

Cells were seeded at a density of $5 \times 10^{4}$ cells per chamber of an eight-well chamber slide and incubated as normal $\left(37^{\circ} \mathrm{C}, 5 \% \mathrm{CO}_{2}\right.$, supplier-recommended media) for $24 \mathrm{~h}$. The cells were cooled to $4^{\circ} \mathrm{C}$ for $20 \mathrm{~min}$ to minimise membrane turnover and media were removed and the cells washed carefully in cold DPBS. Then $1 \mu \mathrm{g} \mathrm{ml}^{-1}$ anti-CD70 antibody BU69 (Ancell Corporation, Bayport, MN, USA) and isotype control antibody were prepared in $200 \mu \mathrm{l}$ cold serum free DMEM/F12 media, added to their respective chambers and incubated at $4{ }^{\circ} \mathrm{C}$ for $20 \mathrm{~min}$. Cells were washed twice with DPBS and the $0 \mathrm{~h}$ samples fixed in $4 \%$ paraformaldehyde for $10 \mathrm{~min}$. Warmed media were added to the remaining chambers and the cells incubated at $37^{\circ} \mathrm{C}$ for 2,4 and $24 \mathrm{~h}$ before fixation. After fixation, the cells were washed twice in DPBS, then blocked/ permeabilised for $20 \mathrm{~min}$ at RT in $0.1 \%$ saponin $/ 5 \%$ donkey serum in DPBS. Biotinylated goat anti-mouse IgG diluted $1: 200$ $\left(10 \mu \mathrm{g} \mathrm{ml}^{-1}\right)$ in $0.1 \%$ saponin $/ 5 \%$ donkey serum/PBS was then added for $1 \mathrm{~h}$ at RT followed by three washes in DPBS. ExtravidinCy3 (Sigma-Aldrich, Poole, UK) diluted 1:500 in 0.1\% saponin $/ 5 \%$

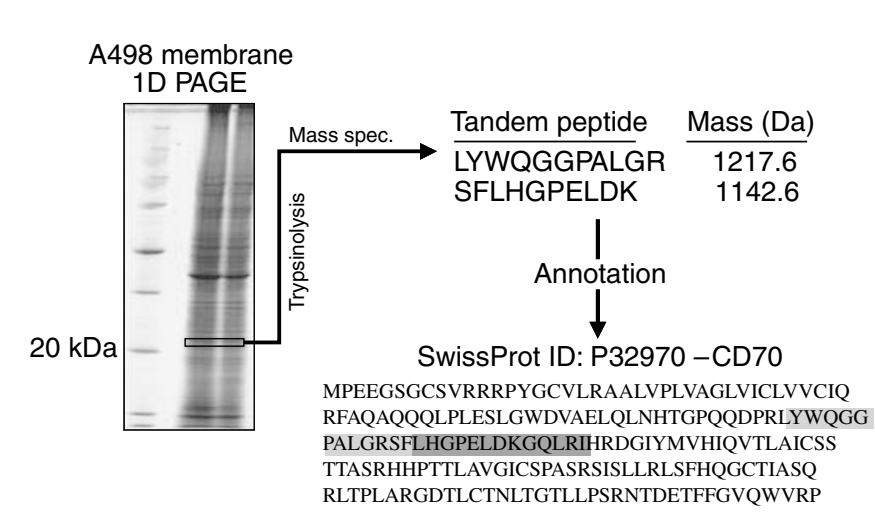

Figure I Proteomic discovery of CD70 in the plasma membrane fraction of A498 and SW839 renal carcinoma-derived cell lines. The plasma membrane fraction of A498 and SW839 cell lines was resolved by onedimensional PAGE. The proteins contained within $0.5 \mathrm{~mm}$ consecutive slices of the gel were subjected to trypsinolysis and analysed by MALDITOF mass spectrometry with selected masses characterised further by MS/ MS using a quadrupole TOF mass spectrometer equipped with a nanospray ion spray. Using the SEQUEST search program, two uninterpreted ion fragmentation mass spectra representing peptides LYWQGGPALGR and SFLHGPELDK identified from the tryptic peptides isolated from a gel slice taken at around $23 \mathrm{kDa}$ were searched against a FASTA database of public domain proteins and were found to match CD70 (SwissProt accession P32970). 
donkey serum/PBS was added for $30 \mathrm{~min}$ followed by three washes in PBS. The cells were then mounted in fluorescence enhancing mounting media (DakoCytomation, Ely, UK) and examined using a Leica Microsystems fluorescence microscope with $\times 63$ oil immersion objective.

\section{Saporin-mediated cell killing assay}

Antibodies conjugated to the ribosome-inactivating toxin Saporin (Thorpe et al, 1985) were used to evaluate the ability of CD70 to perform as a therapeutic antibody target. Briefly, A498 cells were harvested and resuspended at $1 \times 10^{5} \mathrm{cells} \mathrm{ml}^{-1}$. An aliquot of cells $(200 \mu \mathrm{l})$ was added to each well of a 96-well tissue culture plate and grown to confluence. Cells were washed with PBS and labelled on ice with anti-CD70 antibody BU69 (Ancell Corporation, Bayport, MN, USA) or control IgG1 primary (Serotec Ltd, Oxford, UK) at a range of concentrations. After $30 \mathrm{~min}$, labelled cells were washed three times with cold PBS. Saporin-conjugated goat anti-mouse antibody, Hum-Zap (Advanced Targeting Systems, San Diego, CA, USA), or control antibody was then added to each well to a final concentration of $5 \mu \mathrm{g} \mathrm{ml}^{-1}$. After incubation for $24 \mathrm{~h}$, cells and debris were harvested from the plate using trypsin digestion and centrifugation. The recovered cell pellet was then resuspended in $1 \mathrm{ml}$ PBS containing propidium iodide $\left(0.1 \mu \mathrm{g} \mathrm{ml}^{-1}\right.$ final $)$ and percent cell death in each sample calculated by propidium iodide exclusion analysis using a FACScalibur flow cytometer (BectonDickinson, Oxford, UK) equipped with Cellquest Pro software.

\section{Real-time quantitative RT - PCR}

Real-time quantitative RT-PCR analysis of gene expression (Morrison et al, 1998) was carried out on first-strand cDNA derived from RNA isolated from samples of normal tissues (Clontech, Palo Alto, CA, USA) and RCC tissues (Ardais

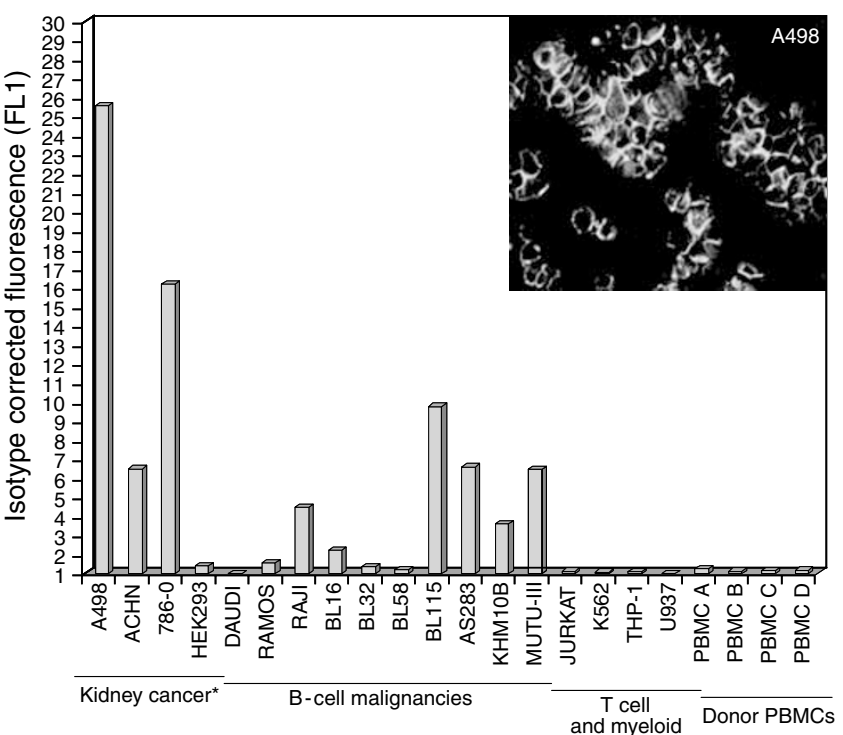

Figure 2 CD70 protein is expressed at the cell-surface of kidney cancerderived cell lines. An anti-CD70 mAb was used in the context of FACS analysis to determine relative cell-surface protein levels for A498, 786-0, SW839 and ACHN renal carcinoma cell lines. The immortalised embryonic kidney line HEK293 was included as a 'normal' kidney cell line control. In addition, as CD70 expression was first described in B/T cells, a panel of cell lines with this derivation was included. The CDI9+ or CD3 + subsets of PBMCs were also analysed to confirm the previously observed absence of binding to these cells. Results demonstrated that expression of CD70 was highest in A498 and 786-0 cells. Immunocytochemical analysis was subsequently used to support the finding that CD70 antibody binds to the surface of A498 cells (inset).
Corporation, Lexington MA, USA; Peterborough Tissue Bank, Peterborough, UK). All clinical samples were obtained with informed patient consent and ethical approval. Each PCR reaction contained $10 \mathrm{ng}$ first-strand cDNA (prepared from each mRNA sample using Superscript ${ }^{\mathrm{TM}}$ reverse transcriptase, Life Technologies, Carlsbad, CA, USA), SYBR green sequence detection reagents (Applied Biosystems, Foster City, CA, USA) and sense and antisense primers. All primer pairs traverse at least one intron and test products have been sequenced to confirm specificity before use in these assays. PCR products from all samples were analysed on agarose gels and positives shown to contain a single PCR product of the size predicted from cDNA. No fragments of the size predicted from genomic DNA were detected in any samples, demonstrating the complete absence of genomic DNA contamination. All reactions were run twice and any samples showing a $>10 \%$ variation in copy number excluded from the analysis. The CD70 primers used were as follows: F, gctgctttggtcccattggtcg (exon 1 ); R, gaggtcctgtgtgattcagctg (exon $2 / 3$ junction; $141 \mathrm{bp}$ product). The CA9 primers used were as follows: F, cagtgcctatgagcagttgctg (exon 6); R, cttagcactcagcatcactgtc (exon 7; 204 bp product). The PCR conditions used for both sets of primers were one cycle at $50^{\circ} \mathrm{C}$ for $2 \mathrm{~min}$, one cycle at $95^{\circ} \mathrm{C}$ for $10 \mathrm{~min}$, and 40 cycles of $95^{\circ} \mathrm{C}$

Table I List of frozen human malignant tissues immunostained with a monoclonal anti-CD70 antibody

\begin{tabular}{|c|c|c|}
\hline Tumour type & No. of cases & Positivity \\
\hline \multicolumn{3}{|l|}{ Bladder } \\
\hline Transitional cell carcinoma & 2 & - \\
\hline Brain & I & - \\
\hline \multicolumn{3}{|l|}{ Breast } \\
\hline Primary invasive ductal carcinoma & 11 & - \\
\hline \multicolumn{3}{|l|}{ Breast node } \\
\hline Invasive carcinoma & 2 & - \\
\hline \multicolumn{3}{|l|}{ Colon } \\
\hline Adenocarcinoma & 2 & - \\
\hline \multicolumn{3}{|l|}{ Kidney } \\
\hline Renal papillary carcinoma & 3 & - \\
\hline Clear cell carcinoma & 20 & 16 \\
\hline Oncocytoma & I & - \\
\hline Sarcomatoid & 1 & - \\
\hline Transitional cell carcinoma & 1 & - \\
\hline Neuroblastoma & I & - \\
\hline Chromophobe & I & - \\
\hline Wilms tumour & 3 & - \\
\hline \multicolumn{3}{|l|}{ Liver } \\
\hline Hepatoblastoma & । & - \\
\hline \multicolumn{3}{|l|}{ Lymphoma } \\
\hline Follicular & 8 & - \\
\hline Lymphoblastic & 4 & 2 \\
\hline Large cell lymphoma & 6 & 4 \\
\hline B-chronic lymphoid leukaemia & 2 & - \\
\hline \multicolumn{3}{|l|}{ Skin } \\
\hline Melanoma & 1 & - \\
\hline \multicolumn{3}{|l|}{ Thyroid } \\
\hline Adenocarcinoma & । & - \\
\hline \multicolumn{3}{|l|}{ Lung } \\
\hline Adenocarcinoma & 9 & I \\
\hline Squamous carcinoma & 8 & - \\
\hline Clear cell carcinoma & I & - \\
\hline
\end{tabular}

The number of cases tested for each tumour type is shown along with the number that were CD70 positive (- denotes that none of the tissues tested were CD70 positive) 

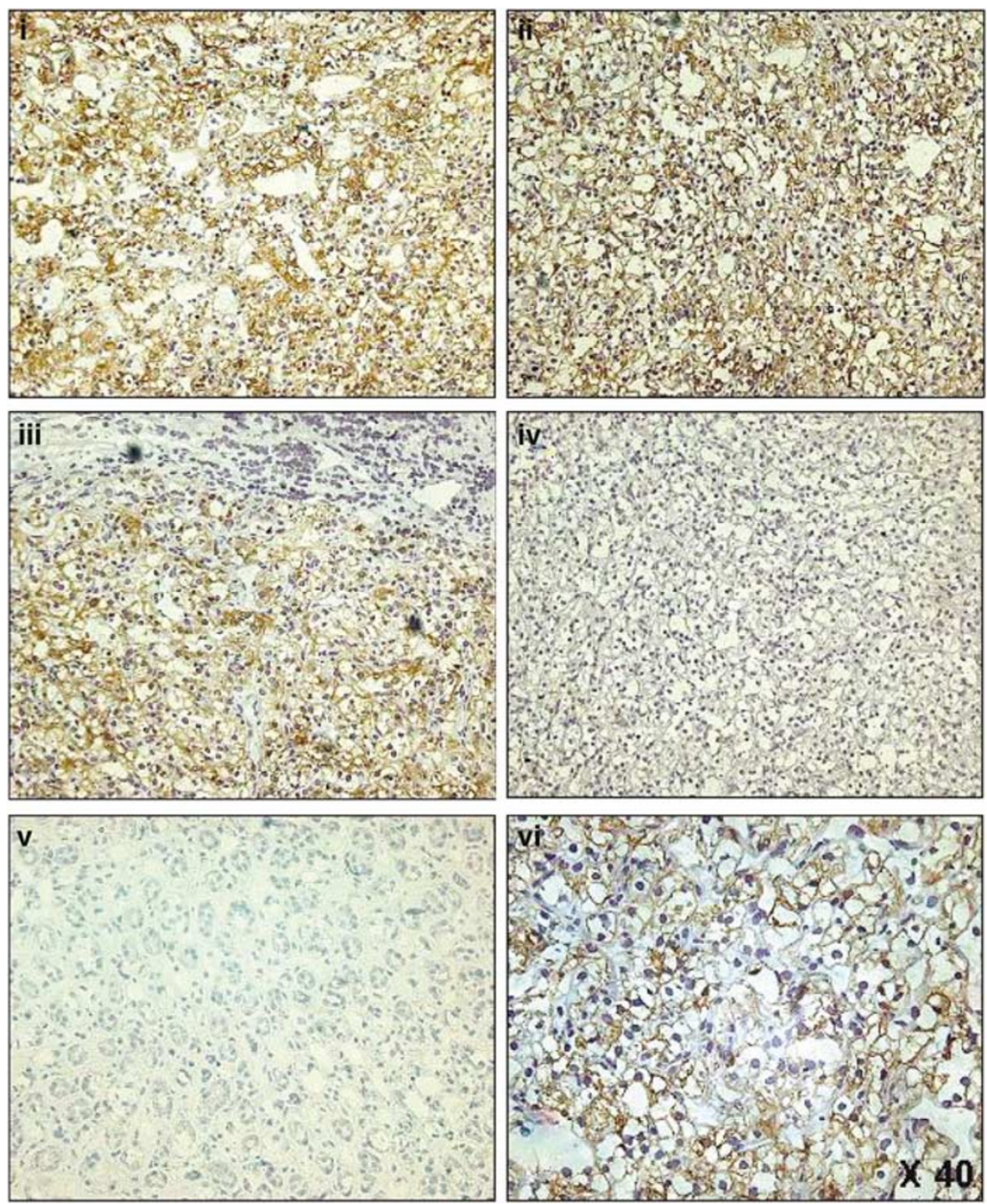

Figure 3 Immunohistochemical analysis of CD70 in RCCs. CD70 expression throughout the carcinoma tissues of frozen sections of clear cell RCC (ccRCC) is shown (panels i-iii) relative to an isotype matched control antibody (panel iv). CD70 expression was not seen in normal kidney tissues (panel v). Panels $i-v$ all show images at $\times 20$ magnification. Panel vi shows a higher power $(\times 40)$ image of a CD70-positive ccRCC tissue demonstrating the plasma membrane expression of CD70 in the carcinoma cells.

for $15 \mathrm{~s}, 65^{\circ} \mathrm{C}$ for $1 \mathrm{~min}$. Reaction products were assayed on an $\mathrm{ABI}$ Prism 7700 Sequence Detection System (Applied Biosystems, Foster City, CA, USA) and the accumulation of PCR product was measured in real time as the increase in SYBR green fluorescence. Data were analysed using the Sequence Detector program v1.6.3 (Applied Biosystems, Foster City, CA, USA). Standard curves relating initial template copy number to fluorescence and amplification cycle were generated using the amplified PCR product as a template, and were used to calculate copy number in each sample. Data were expressed as copy number per nanogram cDNA.

\section{RESULTS}

\section{Proteomic discovery of CD70 in RCC-derived cell lines}

Purified cell membrane protein preparations were isolated from the A498, SW839 and CAKI-2 RCC-derived cell lines and individually separated by one-dimensional PAGE. Sequential $0.5 \mathrm{~mm}$ gel slices containing the proteins were subjected to trypsinolysis, and the resulting peptide fragments analysed by MALDI-TOF and MS/MS (Figure 1). Two ion fragmentation mass spectra from two tryptic peptides of masses 1217.6 and $1142.6 \mathrm{Da}$, respectively, were identified in gel slices corresponding to a molecular weight $23 \mathrm{kDa}$ from the A498 and SW839 RCC-derived cell lines (Figure 1). Using the SEQUEST algorithm (Link et al, 1999), interpretations of these spectra were searched against a FASTA database of public domain proteins and found to uniquely match two peptide sequences (LYWQGGPALGR and SFLHGPELDK) that unambiguously identify the CD70 antigen (Swiss-Prot accession P32970), a type II transmembrane receptor also known as CD27L or TNF ligand superfamily member 7 (TNFSF7) (Figure 1).

To confirm and determine the relative cell-surface expression levels of CD70 in RCC-derived cell lines, the anti-CD70 mAb BU69 was used in FACS analysis. This antibody was selected for FACS and immunocytochemistry as it gave more consistent results in these analyses. The A498, 786-0, and ACHN RCC cell lines and the immortalised HEK293 'normal' kidney cell line were included for FACS analysis, and, as CD70 expression was first described in 

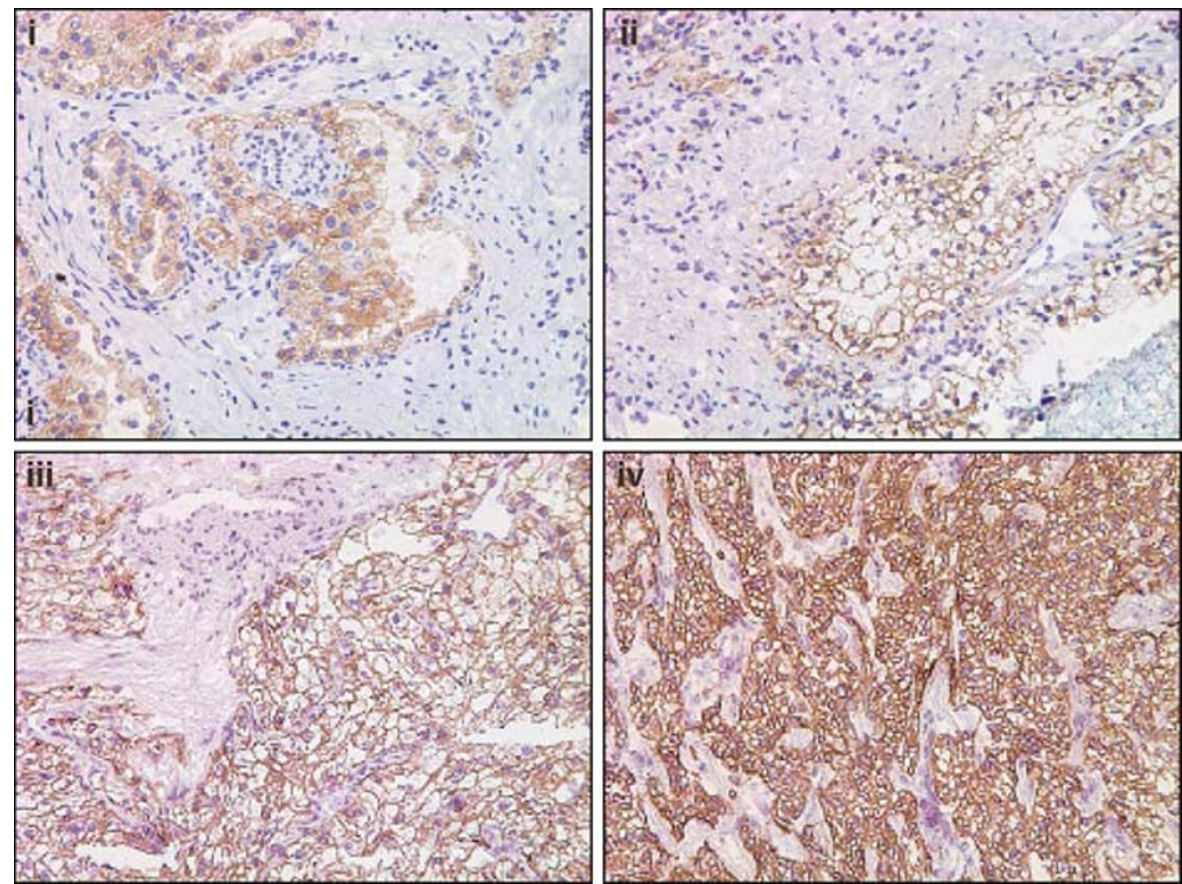

Figure 4 Immunohistochemical analysis demonstrating that CD70 expression is retained in metastatic tissues derived from primary ccRCC donors. CD70 expression in a primary ccRCC tissue (panel i) is shown alongside expression in a section of adrenal gland metastasis from the same donor (panel ii). Panels iii and iv show CD70 expression in retroperitoneal region metastasis and lung metastasis respectively from two separate donors with primary ccRCC. Magnification $\times 20$.

activated $\mathrm{B}$ and $\mathrm{T}$ cells, a panel of cell lines with this derivation was also included in the analysis as were the CD19+ and CD3+ subsets of PBMCs. Results demonstrated that expression of CD70 was highest in the A498, then 786-0 RCC-derived cells (Figure 2). Expression in the ACHN cell line was approximately five-fold lower than on the A498 cell line. Cell-surface expression was also detected on the Raji, BL115, AS283, KHM10B and Mutu-III cell lines that are all derived from B-cell malignancies; however, expression on these cell lines was 2-3-fold less than the A498 and 786-O cells (Figure 2). There was no detectable CD70 expression in the $\mathrm{T}$ and myeloid cell lines or donor PBMCs analysed. Immunocytochemical analysis with BU69 antibody demonstrated strong membrane reactivity in A498 cells (Figure 2). Scatchard analysis showed that A498, 786-O and ACHN cell lines endogenously expressed 342000,265000 and 33000 receptors per cell, respectively. FACS and mRNA analyses were also used to determine whether the RCC cell lines expressing CD70 also expressed CD27, the costimulatory receptor for CD70. No detectable CD27 expression could be seen on any of the RCC cell lines tested (data not shown).

\section{CD70 is expressed in primary and metastatic RCC tissues}

Having discovered high levels of cell-surface CD70 expression on a number of RCC-derived cell lines, we sought to investigate CD70 expression in clinical RCC tissues. Immunohistochemistry on frozen tissue sections was used to determine expression of CD70 on a number of different types of malignant tissues including 30 kidney cancer donor tissues. The results of this analysis are shown in Table 1 . In total, 90 donor tumour tissues were examined; however, only RCC tissues showed strong staining with the anti-CD70 antibody, with 16 out of $30(53 \%)$ cases showing CD70 immunoreactivity. Of all the other tumour tissues examined, weak staining was observed in two of four cases of lymphoblastic lymphoma, four of six cases of large cell lymphoma and one of nine cases of lung adenocarcinoma (Table 1).
Examples of CD70 immunostaining of RCC tissues but not normal kidney are shown in Figure 3.

Expression of CD70 was also examined in 11 clear cell RCC (ccRCC) metastatic patient tissues, two of which had matched primary ccRCC tumour tissue for comparison. Eight out of eleven (73\%) metastatic tissues showed some CD70 expression, and for the two patients with matched primary and metastatic tissues the intensity of CD70 immunostaining of the primary ccRCC and metastasis was in each case the same. Examples of CD70 immunostaining of metastatic ccRCC tissues are shown in Figure 4, in which patient matched primary and metastatic ccRCC CD70 immunostaining is shown (Figure $4, \mathrm{i}$ and ii).

\section{CD70 is rapidly internalised on antibody binding to RCC-derived cell lines}

To determine whether CD70 is a suitable target for cytotoxicconjugated antibody therapy, we investigated CD70 internalisation on antibody binding. An anti-CD70 antibody, BU69, which is suitable for flow cytometric applications, was added to live A498 and 786-O cells that had been cooled to minimise membrane turnover. After a $20 \mathrm{~min}$ incubation at $4^{\circ} \mathrm{C}$, a proportion of the cells were fixed to represent a $0 \mathrm{~h}$ time point, and warmed serum was added to the remainder of the cells that were subsequently fixed at 1,2 and $4 \mathrm{~h}$ time points. Evidence of internalisation of the anti-CD70 antibody-receptor complex was visualised immunocytochemically as described in Materials and methods (Figure 5). Results showed that for both A498 and $786-\mathrm{O}$ cells at $0 \mathrm{~h}$, there was clear plasma membrane staining only with the anti-CD70 antibody. However, after $1 \mathrm{~h}$ of incubation, there was clear internalisation of the antibodyreceptor complex as evidenced by a reduction in the intensity of plasma membrane staining and appearance of antibody-containing vesicles within the cells (Figure 5). Internalisation was even more pronounced at $2 \mathrm{~h}$ and after $4 \mathrm{~h}$ the antibody had completely internalised. 
A
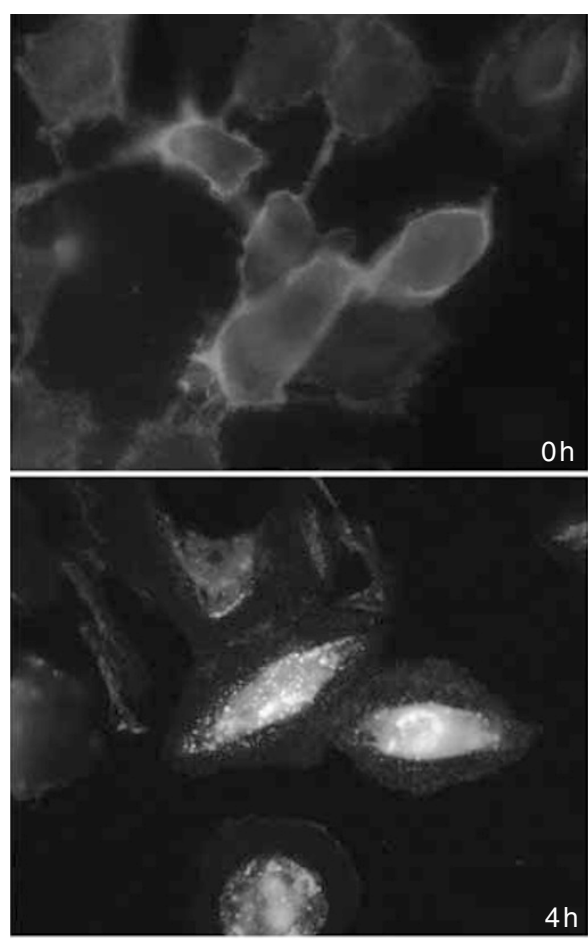

$4 \mathrm{~h}$

B

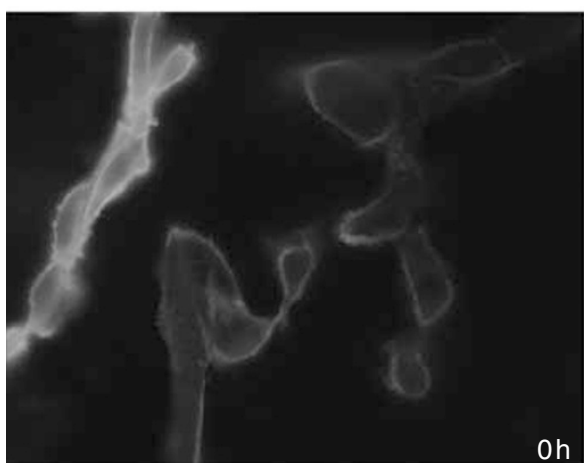

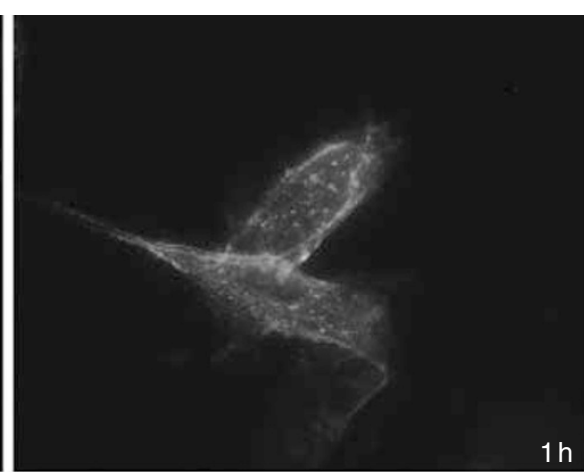
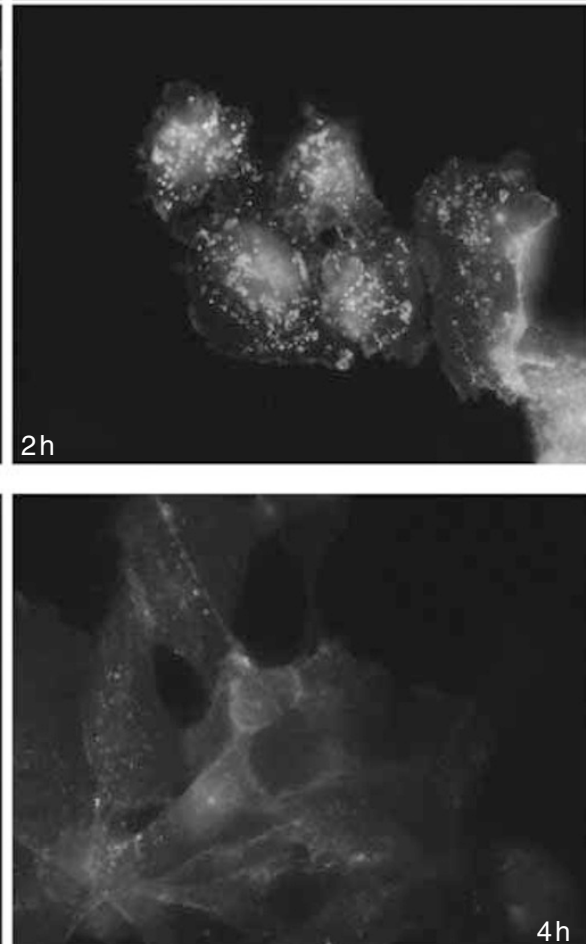

Figure 5 Immunocytochemical analysis demonstrating rapid CD70 internalisation on anti-CD70 antibody binding. (A) A498 cells showing anti-CD70 antibody binding to the plasma membrane after incubation at $4^{\circ} \mathrm{C}$ for $20 \mathrm{~min}(0 \mathrm{~h})$ followed by clear evidence of internalisation of the antibody (endosomal compartmentalisation) at I, 2 and $4 \mathrm{~h}$ after the addition of growth media at $37^{\circ} \mathrm{C}$. (B) $786-\mathrm{O}$ cells showing anti-CD70 antibody membrane staining of the cells at $\mathrm{Oh}$ and internalisation after $4 \mathrm{~h}$ incubation.

To investigate the ability of the anti-CD70 antibody-receptor complex to internalise with a toxin and kill RCC cell lines endogenously expressing CD70, we coincubated the anti-CD70 antibody with an anti-mouse secondary antibody that was conjugated to saporin before addition to the A498 cell line for $24 \mathrm{~h}$. This demonstrated that using $10 \mu \mathrm{g} \mathrm{ml}^{-1}$ primary antibody in the presence of $5 \mu \mathrm{g} \mathrm{ml}^{-1}$ saporin-conjugated secondary antibody, approximately $45 \%$ of the cells were killed by the addition of antiCD70 antibody (Figure 6). In contrast, all the appropriate control incubations showed approximately $5 \%$ cell death. A range of other primary antibody concentrations was used, with significant cell killing (25\%) observed with $0.08 \mu \mathrm{g} \mathrm{ml}^{-1}$, the lowest concentration of primary antibody tested (Figure 6).

\section{CD70 exhibits a more restricted normal tissue distribution and higher prevalence of expression in RCC tissues than CA9}

CA9 is a known antigen currently being targeted for RCC immunotherapy (Divgi et al, 1998; Steffens et al, 1999; Uemura et al, 1999; Grabmaier et al, 2000; Li et al, 2001; Bui et al, 2003; Kennett, 2003). To compare expression of CD70 with CA9, we performed real-time quantitative RT-PCR analysis on multiple normal tissues and clinical RCC samples (Figure 7). These data showed that there was no detectable CD70 mRNA in any of the 29 normal tissues examined; in the thymus, reported expression of CD70 in the medullary epithelium (Hintzen et al, 1994; Tesselaar et $a l, 2003$ ) was likely diluted below the limit of detection by the presence in this tissue of other, non-expressing cell types. In contrast, there were high levels of CA9 in the stomach and testis, and to a lesser extent in the small intestine and prostate. In the clinical RCC samples, the overall level and prevalence of CD70 mRNA was greater than that of CA9 (Figure 7).

\section{DISCUSSION}

Identification of antigens expressed specifically and at high levels on kidney cancer cells is a key step in the development of effective immunotherapies for this poorly treated disease. In this paper, we 
describe the identification of CD70 using proteomic analysis of the plasma membrane fraction of RCC-derived cell lines. CD70 has a very restricted normal tissue expression but was found to be

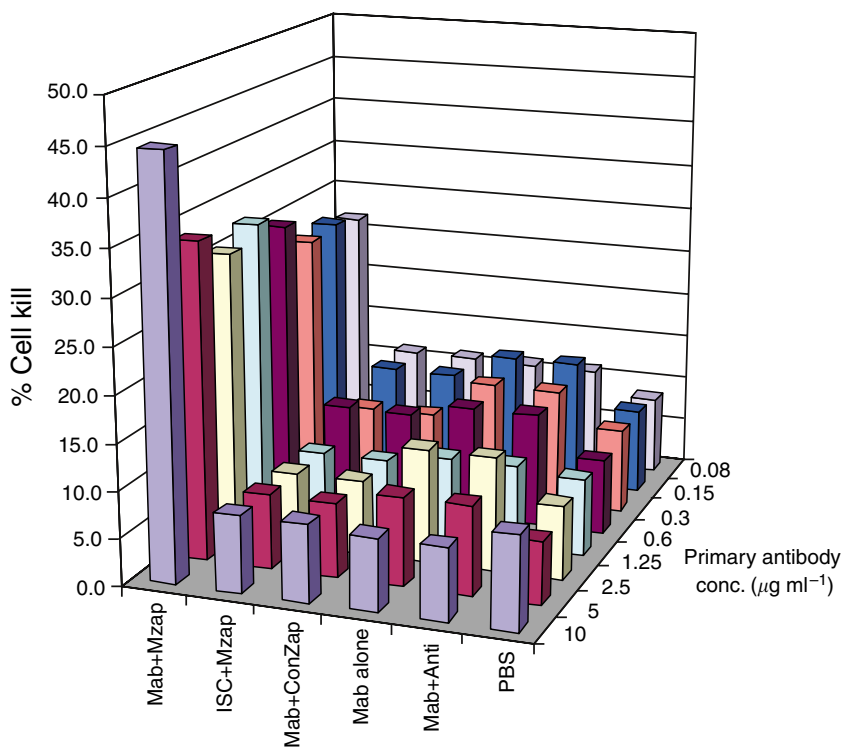

Figure 6 Targeting CD70 on A498 cells with an anti-CD70 mAb and Saporin-conjugated secondary antibody results in specific cell kill. Histograms show the \% cell kill following incubation in a range of primary antibody concentrations. High levels of cell death were observed only for cells incubated with anti-CD70 and Saporin-conjugated secondary antibody. Propidium iodide exclusion analysis was used to calculate the \% cell kill. Mab = anti-CD70, Mzap = goat anti-mouse Saporin conjugate, $I S C=|g G|$ isotype control, ConZap=Saporin-conjugated goat IgG, anti=goat anti-mouse lgG. Data shown are representative of three separate experiments. expressed on 16 of 30 RCC clinical specimens and expression was retained in metastatic tissues from ccRCC. In addition, we have demonstrated that binding of an anti-CD70 antibody to cell lines endogenously expressing CD70 results in the rapid internalisation of the antibody-receptor complex, and can mediate cell killing via a toxic immunoconjugate.

CD70 is a type II transmembrane protein that was originally identified as a member of the TNF receptor superfamily with an expression pattern in normal tissues restricted to germinal centre B cells, stromal cells of the thymic medulla and scattered T cells (Goodwin et al, 1993; Bowman et al, 1994; Hintzen et al, 1994). Subsequent studies have described overexpression of CD70 protein in mantle cell lymphoma samples (Zhu et al, 2002); on chronic lymphocytic leukaemia B cells (Lens et al, 1995; Ranheim et al, 1995); and in the tumour cells of thymic carcinomas (Hishima et al, 2000), undifferentiated nasopharyngeal carcinomas (Agathanggelou et al, 1995), gliomas and meningiomas (HeldFeindt and Mentlein, 2002). Additionally, CD70 overexpression was detected in a multidrug-resistant colonic cell line (SW620MDR) (Fan et al, 2004), and as an inducible gene in TNF-alphastimulated human bronchial-epithelial cell line BEAS-2B (Wolf et al, 2002), and irradiated glioma cell lines (Wischhusen et al, 2002). Our study also identified CD70 expression on B-cell malignancy-derived cell lines using FACS analysis (Figure 2), and on six out of twenty clinical lymphoma specimens by immunostaining (Table 1). Anti-CD70 immunostaining on positive RCC sections was much stronger than that of the lymphomas in our study, and quantitative RT - PCR results also showed an overall higher level of CD70 gene transcription in RCC, indicating that the protein is highly over-expressed.

CD70 is the ligand for CD27; studies of this interaction have shown that CD70 promotes cell survival and expansion of antigenprimed $\mathrm{CD} 8+\mathrm{T}$ cells, formation of memory $\mathrm{T}$ cells and proliferation of B cells (Brown et al, 1995; Hintzen et al, 1995; Borst et al, 2005). CD70 protein, whether expressed on dendritic cells (Hintzen et al, 1995), B cells (Rowley and Al-Shamkhani, 2004), tumour cells (Arens et al, 2001), or introduced as soluble

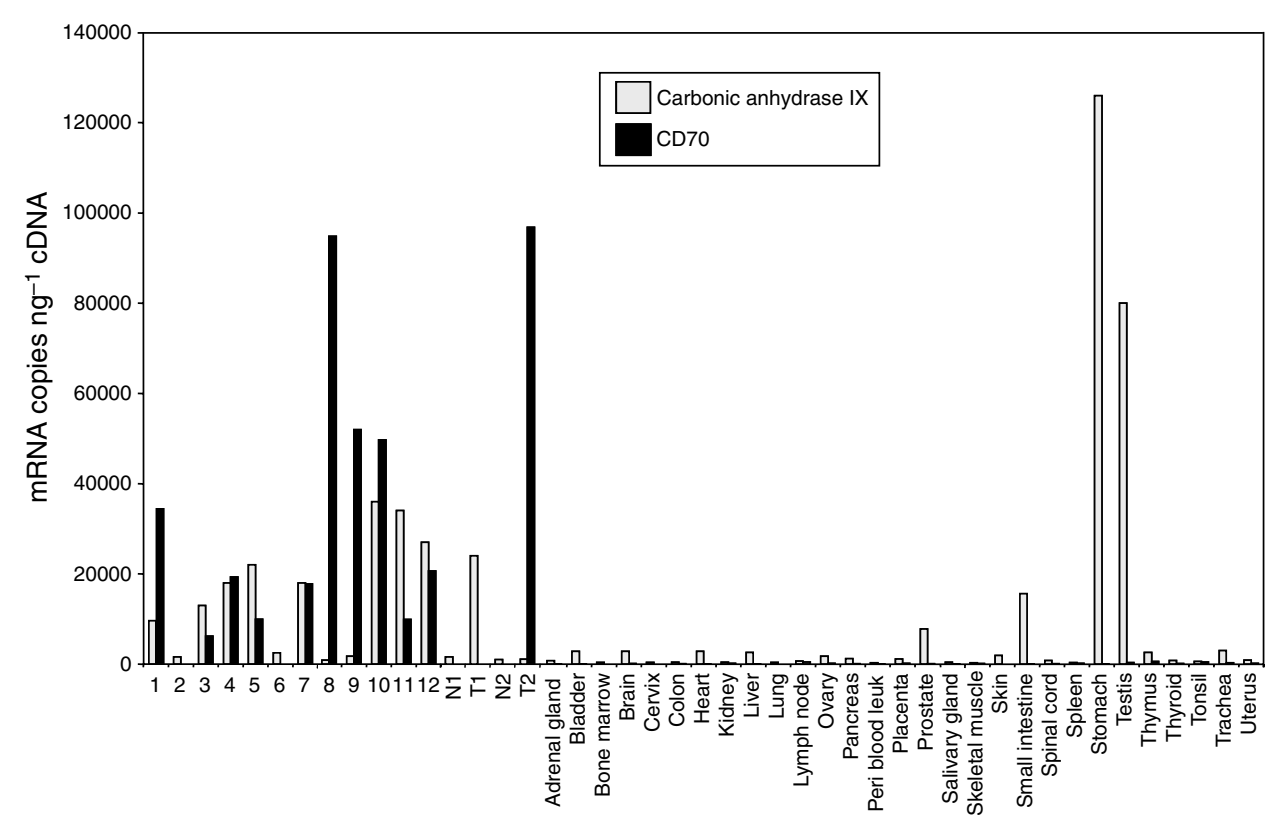

Figure 7 Comparison of the mRNA expression levels of CD70 and CA9 in normal and RCC tissues. Real-time quantitative RT - PCR analysis was used to calculate the mRNA copies per ng CDNA of CD70 and CA9 in a range of 29 normal tissues and I 4 renal cancers: I = renal cell carcinoma containing both granular and clear cells; $2=$ chromophobe adenocarcinoma; $3=$ RCC having a tubular pattern with slightly oxyphilic cells; $4=$ unknown kidney cancer; $5=$ transitional cell carcinoma arising from renal pelvis; $6=$ unknown kidney cancer; $7=$ renal cell carcinoma of clear cell type; $8=$ Wilms tumour; $9-12$ = clear cell renal carcinoma; two RCC donors with matched adjacent normal tissue $(\mathrm{N}=$ normal, $\mathrm{T}=$ tumour). 
protein (Kelly et al, 2002), promotes the survival and expansion of antigen-primed $\mathrm{CD} 8+\mathrm{T}$ cells in the mouse, through dosedependent stimulation of CD27 activity. CD70-CD27 interactions may also have a role in memory T-cell formation, which is reduced by CD70 blockade and enhanced by CD70 overexpression or recombinant protein infusion (Borst et al, 2005). The effect of $\mathrm{CD} 70$ on $\mathrm{B}$ cells is less understood, although in vitro studies suggest that the CD70-CD27 interaction promotes plasma cell differentiation (Cormary et al, 2004), whereas other experiments have demonstrated CD70-driven B-cell proliferation and immunoglobulin synthesis (Agematsu et al, 1995; Kobata et al, 1995). Effects in humans may be more significant than in mice owing to higher and more consistent expression of CD27 in human B cells.

Our studies showed a high-level expression of CD70 on RCC cells that might be expected to induce a strong immune response against the tumour. Frequent expression of CD70 on RCC was recently also reported by Junker et al (2005). Although RCC is known to be a highly immunogenic tumour, it is also a very aggressive cancer that is clearly able to escape immune surveillance. Many other factors are involved in the generation of an immune response and it has already been shown that CD70-driven CD8 + T-cell expansion is dependent upon priming. The high expression of CD70 observed in RCC may be owing to a partial Tcell induction response, or even simply an incidental result of activation/amplification of a genomic locus.

We also demonstrated that CD70 on RCC cell lines internalises rapidly on specific antibody binding, and that this internalisation can be utilised to transport active cytotoxic molecules into cancer cells. This was corroborated by a recent paper describing an antiCD70 immunoconjugate of doxorubicin that displayed antibodymediated toxicity against RCC cell lines (Jeffrey et al, 2006).

The development of effective toxin-conjugated immunotherapies will require target antigens that exhibit a highly restricted expression profile in normal tissues, high expression in primary and metastatic cancer tissues and rapid internalisation of the antigen-antibody-toxin complex. CD70 is an antigen that fulfils all of these criteria, in that it is highly overexpressed in a large proportion of renal carcinomas, whereas normal tissue expression is low and restricted to a subset of peripheral blood lymphocytes, and internalises in response to specific antibody binding.

\section{REFERENCES}

Adam PJ, Boyd R, Tyson KL, Fletcher GC, Stamps A, Hudson L, Poyser HR, Redpath N, Griffiths M, Steers G, Harris AL, Patel S, Berry J, Loader JA, Townsend RR, Daviet L, Legrain P, Parekh R, Terrett JA (2003) Comprehensive proteomic analysis of breast cancer cell membranes reveals unique proteins with potential roles in clinical cancer. J Biol Chem 278: $6482-6489$

Agathanggelou A, Niedobitek G, Chen R, Nicholls J, Yin W, Young LS (1995) Expression of immune regulatory molecules in Epstein-Barr virus-associated nasopharyngeal carcinomas with prominent lymphoid stroma. Evidence for a functional interaction between epithelial tumor cells and infiltrating lymphoid cells. Am J Pathol 147: 1152-1160

Agematsu K, Kobata T, Yang FC, Nakazawa T, Fukushima K, Kitahara M, Mori T, Sugita K, Morimoto C, Komiyama A (1995) CD27/CD70 interaction directly drives B cell IgG and IgM synthesis. Eur J Immunol 25: $2825-2829$

Arens R, Tesselaar K, Baars PA, van Schijndel GM, Hendriks J, Pals ST, Krimpenfort P, Borst J, van Oers MH, van Lier RA (2001) Constitutive $\mathrm{CD} 27 / \mathrm{CD} 70$ interaction induces expansion of effector-type $\mathrm{T}$ cells and results in IFNã-mediated B cell depletion. Immunity 15: 801-812

Borst J, Hendriks J, Xiao Y (2005) CD27 and CD70 in T cell and B cell activation. Curr Opin Immunol 17: 275-281

Bowman MR, Crimmins MA, Yetz-Aldape J, Kriz R, Kelleher K, Herrmann $S$ (1994) The cloning of CD70 and its identification as the ligand for CD27. J Immunol 152: 1756-1761

Brown GR, Meek K, Nishioka Y, Thiele DL (1995) CD27-CD27 ligand/ CD70 interactions enhance alloantigen-induced proliferation and cytolytic activity in CD8+ T lymphocytes. J Immunol 154: 3686-3695

Bui MH, Seligson D, Han KR, Dorey FJ, Huang Y, Horvath S, Leibovich BC, Chopra S, Liao SY, Stanbridge E, Lerman MI, Palotie A, Figlin RA, Belldegrun AS (2003) Carbonic anhydrase IX is an independent predictor of survival in advanced renal clear cell carcinoma: implications for prognosis and therapy. Clin Cancer Res 9: 802-811

Cormary C, Gonzalez R, Faye JC, Favre G, Tilkin-Mariame AF (2004) Induction of T-cell antitumor immunity and protection against tumor growth by secretion of soluble human CD70 molecules. Cancer Gene Ther 11: $497-507$

Divgi CR, Bander NH, Scott AM, O'Donoghue JA, Sgouros G, Welt S, Finn RD, Morrissey F, Capitelli P, Williams JM, Deland D, Nakhre A, Oosterwijk E, Gulec S, Graham MC, Larson SM, Old LJ (1998) Phase I/II radioimmunotherapy trial with iodine-131-labeled monoclonal antibody G250 in metastatic renal cell carcinoma. Clin Cancer Res 4: 2729-2739

Fan CW, Chan CC, Chao CC, Fan HA, Sheu DL, Chan EC (2004) Expression patterns of cell cycle and apoptosis-related genes in a multidrug-resistant human colon carcinoma cell line. Scand J Gastroenterol 39: 464-469

Goodwin RG, Alderson MR, Smith CA, Armitage RJ, VandenBos T, Jerzy R, Tough TW, Schoenborn MA, Davis-Smith T, Hennen K (1993) Molecular and biological characterization of a ligand for CD27 defines a new family of cytokines with homology to tumor necrosis factor. Cell 73: $447-456$

Grabmaier K, Vissers JL, De Weijert MC, Oosterwijk-Wakka JC, Van Bokhoven A, Brakenhoff RH, Noessner E, Mulders PA, Merkx G, Figdor CG, Adema GJ, Oosterwijk E (2000) Molecular cloning and immunogenicity or renal cell carcinoma-associated antigen G250. Int J Cancer 85: $865-870$

Held-Feindt J, Mentlein R (2002) CD70/CD27 ligand, a member of the TNF family, is expressed in human brain tumors. Int $J$ Cancer 98: $352-356$

Hintzen RQ, Lens SM, Koopman G, Pals ST, Spits H, van Lier RA (1994) CD70 represents the human ligand for CD27. Int Immunol 6: 477-480

Hintzen RQ, Lens SM, Lammers K, Kuiper H, Beckmann MP, van Lier RA (1995) Engagement of CD27 with its ligand CD70 provides a second signal for T cell activation. J Immunol 154: 2612-2623

Hishima T, Fukayama M, Hayashi Y, Fujii T, Ooba T, Funata N, Koike M (2000) CD70 expression in thymic carcinoma. Am J Surg Pathol 24: 742 746

Jeffrey SC, Nguyen MT, Andreyka JB, Meyer DL, Doronina SO, Senter PD (2006) Dipeptide-based highly potent doxorubicin antibody conjugates. Bioorg Med Chem Lett 16: 358-362

Junker K, Hindermann W, von Eggeling F, Diegmann J, Haessler K, Schubert J (2005) CD70: a new tumor specific biomarker for renal cell carcinoma. J Urol 173: 2150-2153

Kammula US (1998) Trends in the safety of high dose bolus interleukin-2 administration in patients with metastatic cancer. Cancer 83: 797-805

Kelly JM, Darcy PK, Markby JL, Godfrey DI, Takeda K, Yagita H, Smyth MJ (2002) Induction of tumor-specific T cell memory by NK-mediated tumor rejection. Nat Immunol 3: 83-90

Kennett RH (2003) Technology evaluation: WX-G250, Wilex/Ludwig Institute for Cancer Research. Curr Opin Mol Ther 5: 70-75

Kobata T, Jacquot S, Kozlowski S, Agematsu K, Schlossman SF, Morimoto C (1995) CD27-CD70 interactions regulate B-cell activation by T cells. Proc Natl Acad Sci USA 92: 11249-11253

Krown SE (1987) Interferon treatment of renal cell carcinoma: current status and future prospects. Cancer 59: 647-651

Lens SM, de Jong R, Hintzen RQ, Koopman G, van Lier RA, van Oers RH (1995) CD27-CD70 interaction: unravelling its implication in normal and neoplastic B-cell growth. Leuk Lymphoma 18: 51-59

Li G, Passebosc-Faure K, Lambert C, Gentil-Perret A, Blanc F, Oosterwijk E, Mosnier JF, Genin C, Tostain J (2001) The expression of G250/mn/CA9 antigen by flow cytometry: its possible implication for detection of micrometastatic renal cancer cells. Clin Cancer Res 7: 89-92

Link AJ, Eng J, Schieltz DM, Carmack E, Mize GJ, Morris DR, Garvik BM, Yates III JR (1999) Direct analysis of protein complexes using mass spectrometry. Nat Biotechnol 17: 676-682 
Morrison TB, Weis JJ, Wittwer CT (1998) Quantification of low-copy transcripts by continuous SYBR Green I monitoring during amplification. Biotechniques 24: $954-958$

Motzer RJ (1999) Survival and prognostic stratification of 670 patients with advanced renal cell carcinoma. J Clin Oncol 17: 2530-2540

Muss HB (1998) The role of biological response modifiers in metastatic renal cell carcinoma. Semin Oncol 15: 30-34

Pastorek J, Pastorekov S, Callebaut I, Mornon JP, Zelnik V, Opavsky R, Zat'ovicova M, Liao S, Portetelle D, Stanbridge EJ (1994) Cloning and characterization of $\mathrm{MN}$, a human tumor associated protein with a domain homologous to carbonic anhydrase and a putative helix-loophelix DNA binding segment. Oncogene 9: 2877-2888

Ranheim EA, Cantwell MJ, Kipps TJ (1995) Expression of CD27 and its ligand, CD70, on chronic lymphocytic leukemia B cells. Blood 85: $3556-$ 3565

Rowley TF, Al-Shamkhani A (2004) Stimulation by soluble CD70 promotes strong primary and secondary CD8+ cytotoxic $\mathrm{T}$ cell responses in vivo. J Immunol 172: 6039-6046

Steffens MG, Boerman OC, de Mulder PH, Oosterhof GO, Witjes JA, Koenders EB, Oyen WJ, Buijs WC, Debruyne FM, Corstens FH, Oosterwijk E (1999) Phase I radioimmunotherapy of metastatic renal cell carcinoma with ${ }^{131}$ I-labeled chimeric monoclonal antibody G250. Clin Cancer Res 5: 3268-3274

Tesselaar K, Xiao Y, Arens R, van Schijndel GM, Schuurhuis DH, Mebius RE, Borst J, van Lier RA (2003) Expression of murine CD27 ligand CD70 in vitro and in vivo. I Immunol 170: 33-40
Thorpe PE, Brown AN, Bremner JA, Foxwell BM, Stirpe F (1985) An immunotoxin composed of monoclonal anti-Thy 1.1 antibody and a ribosome-inactivating protein from Saponaria officinalis: potent antitumor effects in vitro and in vivo. J Natl Cancer Inst 75: 151-159

Uemura H, Nakagawa Y, Yoshida K, Saga S, Yoshikawa K, Hirao Y, Oosterwijk E (1999) MN/CA IX/G250 as a potential target for immunotherapy of renal cell carcinomas. Br J Cancer 81: $741-746$

van Herpen CML, Jansen RLH, Kruit WH, Hoekman K, Groenewegen G, Osanto S, De Mulder PH (2000) Immunochemotherapy with interleukin-2, interferon- $\alpha$ and 5-fluorouracil for progressive metastatic renal cell carcinoma: a multicenter phase II study. $\mathrm{Br} J$ Cancer 82: $772-776$

Wischhusen J, Jung G, Radovanovic I, Beier C, Steinbach JP, Rimner A, Huang H, Schulz JB, Ohgaki H, Aguzzi A, Rammensee HG, Weller M (2002) Identification of CD70-mediated apoptosis of immune effector cells as a novel immune escape pathway of human glioblastoma. Cancer Res 62: $2592-2599$

Wolf K, Schulz C, Riegger GA, Pfeiffer M (2002) Tumour necrosis factoralpha induced CD70 and interleukin-7R mRNA expression in BEAS-2B cells. Eur Respir J 20: 369-375

Yagoda A (1995) Chemotherapy for advanced renal cell carcinoma: 1983 1993. Semin Oncol 22: $42-60$

Zhu Y, Hollmen J, Raty R, Aalto Y, Nagy B, Elonen E, Kere J, Mannila H, Franssila K, Knuutila S (2002) Investigatory and analytical approaches to differential gene expression profiling in mantle cell lymphoma. $\mathrm{Br} J$ Haematol 119: 905-915 